\title{
Relationship between the inflammation/ immune indexes and deep venous thrombosis (DVT) incidence rate following tibial plateau fractures
}

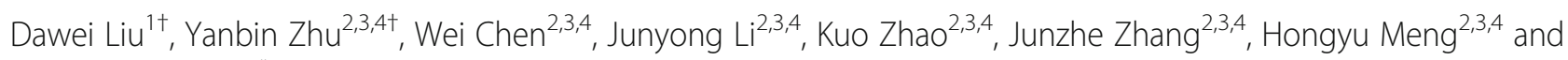
Yingze Zhang ${ }^{2,3,45^{*}}$ (i)

\begin{abstract}
Objective: To determine the relationship between inflammation/immune-based indexes and deep venous thrombosis (DVT) incidence rate following tibial plateau fractures

Methods: Retrospective analysis of a prospectively collected data on patients undergoing surgeries of tibial plateau fractures between October 2014 and December 2018 was performed. Duplex ultrasonography (DUS) was routinely used to screen for preoperative DVT of bilateral lower extremities. Data on biomarkers (neutrophil, lymphocyte, monocyte, and platelet counts) at admission were collected, based on which neutrophil to lymphocyte ratio (NLR), platelet to lymphocyte ratio (PLR), monocyte/lymphocyte (MLR), and systemic immune-inflammation index (SII, neutrophil* platelet/lymphocyte) were calculated. Receiver operating characteristic (ROC) was used to determine the optimal cutoff value for each variable. Multivariate logistic regression analysis was used to evaluate the independent relationship of each biomarker or index with DVT, after adjustment for demographics, co-morbidities, and injury-related variables.
\end{abstract}

Results: Among 1179 patients included, 16.3\% (192/1179) of them had a preoperative DVT. Four factors were identified to be significantly associated with DVT, including open fracture, increased D-dimer level. Among the biomarkers and indexes, only platelet and neutrophil were identified to be independently associated with DVT, and the significance remained after exclusion of open fracture. The other independent variables were elevated D-dimer level (>0.55 mg/L), male gender, and hypertension in the sensitivity analysis with open fractures excluded.

Conclusion: These identified factors are conducive to the initial screening for patients at risk of DVT, individualized risk assessment, risk stratification, and accordingly, development of targeted prevention programs.

Keywords: Inflammatory/immune index, Biomarkers, Deep venous thrombosis, Tibial plateau fractures, Epidemiology

\footnotetext{
*Correspondence: drzhang2013@126.com

${ }^{\dagger}$ Dawei Liu and Yanbin Zhu contributed equally to this work.

${ }^{2}$ Department of Orthopaedic Surgery, The 3rd Hospital of Hebei Medical University, Shijiazhuang 050051, Hebei, P. R. China

${ }^{3}$ Key Laboratory of Biomechanics of Hebei Province, Shijiazhuang 050051, Hebei, P. R. China

Full list of author information is available at the end of the article
}

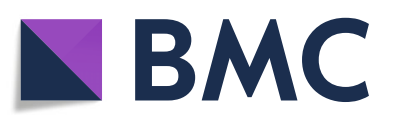

(- The Author(s). 2020 Open Access This article is licensed under a Creative Commons Attribution 4.0 International License, which permits use, sharing, adaptation, distribution and reproduction in any medium or format, as long as you give appropriate credit to the original author(s) and the source, provide a link to the Creative Commons licence, and indicate if changes were made. The images or other third party material in this article are included in the article's Creative Commons licence, unless indicated otherwise in a credit line to the material. If material is not included in the article's Creative Commons licence and your intended use is not permitted by statutory regulation or exceeds the permitted use, you will need to obtain permission directly from the copyright holder. To view a copy of this licence, visit http://creativecommons.org/licenses/by/4.0/. The Creative Commons Public Domain Dedication waiver (http://creativecommons.org/publicdomain/zero/1.0/) applies to the data made available in this article, unless otherwise stated in a credit line to the data. 


\section{Introduction}

Tibial plateau fracture represented $1-2 \%$ of adult fractures and $32 \%$ of peri-knee fractures [1], with a populationbased incidence of 10.3 per 100,000 person-years [2]. It is generally accepted that deep venous thrombosis (DVT) is a significant cause of morbidity, pulmonary embolism, and even mortality, especially in patients with trauma or undergoing major orthopedic surgery $[3,4]$. The previous reports showed that 17.3 to $23.9 \%$ of patients with tibial plateau fracture would develop deep vein thrombosis (DVT) before they were operated $[5,6]$. Extensive and deep understanding of the epidemiologic characteristics of DVT, particularly the relevant risk factors, was of extreme importance in prevention and management. By far, multiple risk factors associated with DVT have been identified, including advanced age, male gender, obesity, a history of DVT or pulmonary embolism, immobility, smoking, or fracture itself [7-10].

In addition to external factors, there are increasing evidences that the internal factors, namely the systemic inflammation/immune response to trauma (hip fracture) or major surgical trauma (arthroplasty), played an important role in the development of DVT. Alexandru et al. [11] found the significant change of some inflammation/immune indexes (neutrophil/lymphocyte ratio (NLR) and platelet/lymphocyte ratio (PLR)) after longbone fracture. Moreover, researchers have identified the significant correlation of NLR, PLR, or monocyte to lymphocyte ratio (MLR) with acute DVT after major orthopedic surgery [12-14]. However, the role of these inflammation/immune indexes in the development of DVT was not consistently significant [15]. Unlike other markers of inflammation, these indexes are calculated by the readily obtained biomarkers from a hemogram with an automated differential, which are routinely measured. If these inexpensive and readily available indexes exhibit their value in predicting DVT after traumatic fractures, they will help identify patients at risk of DVT and improve the specificity in detection of DVT.

As far as we know, specified at tibial plateau fracture, there remains no relevant data on the relationship between inflammation/immune indexes and preoperative DVT occurrence. In this study, we used the prospectively collected data in a level I trauma center to address this issue. Our aims were (1) to identify the optimal cutoff values of biomarkers or their derived indexes, (2) to evaluate their predictive ability for development of DVT, and (3) to evaluate their independent relationship with DVT after adjustment for demographics, co-morbidities, and injury-related characteristics.

\section{Methods}

Data used in this study were obtained from the database of surgical site infection in orthopedic surgery (SSIOS), in which a prospective method was used to collect data on patients who underwent orthopedic surgeries between October 1, 2014, and December 31, 2018, and surveillance of surgical site during hospitalization and telephone follow-up after discharge were conducted to identify surgical site infections. The ethics committee of the 3rd Hospital of Hebei Medical University approved the SSIOS (NO 2014-015-1), and all the participants had written the informed consent.

\section{Inclusion and exclusion criteria}

Patients meeting the following criteria were included: age of 18 years or older, definite diagnosis of tibial plateau fracture, and complete data available. The exclusion criteria were pathological (metastatic) fracture, old fracture ( $>3$ weeks from injury), tibial plateau fracture combined with vascular injury, concurrent fractures in other locations, patients with lower extremity myodynamia abnormality, patients with history of DVT or other thrombotic events, or current use of anticoagulants due to chronic comorbidities.

According to our policy, all patients received basic thromboprophylaxis immediately after admission, consisting of chemical (low molecular weight heparin (LMWH), 2500-4100 IU once daily, subcutaneous injection) and elevation of the injured lower extremity for each patient.

\section{Diagnosis of DVT}

Guideline for the diagnosis and treatment of deep vein thrombosis (3rd edition) proposed by Chinese Medical Association [16] was used to diagnose DVT. Before the operation, routine duplex 106 ultrasonography (DUS) scanning of bilateral lower extremities was performed to detect potential DVT in femoral common, superficial femoral, deep femoral, popliteal, posterior tibial, anterior tibial, and peroneal vein. The positive criteria of DUS scanning were set as noncompressibility, lumen obstruction or filling defect, lack of respiratory variation in above knee segments, and inadequate flow augmentation to calf and foot compression maneuvers [17]. Due to the less clinical significance, superficial or intermuscular vein thrombosis (soleal or gastrocnemius vein thrombosis) were not included $[18,19]$.

\section{Data collection and definition}

Biomarkers or biomarker-derived inflammatory/immune indexes were obtained from hematologic tests carried out after admission and before the definite operation. These data included neutrophil, lymphocyte, monocyte, and platelet counts. The NLR was defined as the neutrophil count divided by lymphocyte count, PLR as the platelet count divided by the lymphocyte count, and MLR as monocyte count divided by lymphocyte count. 


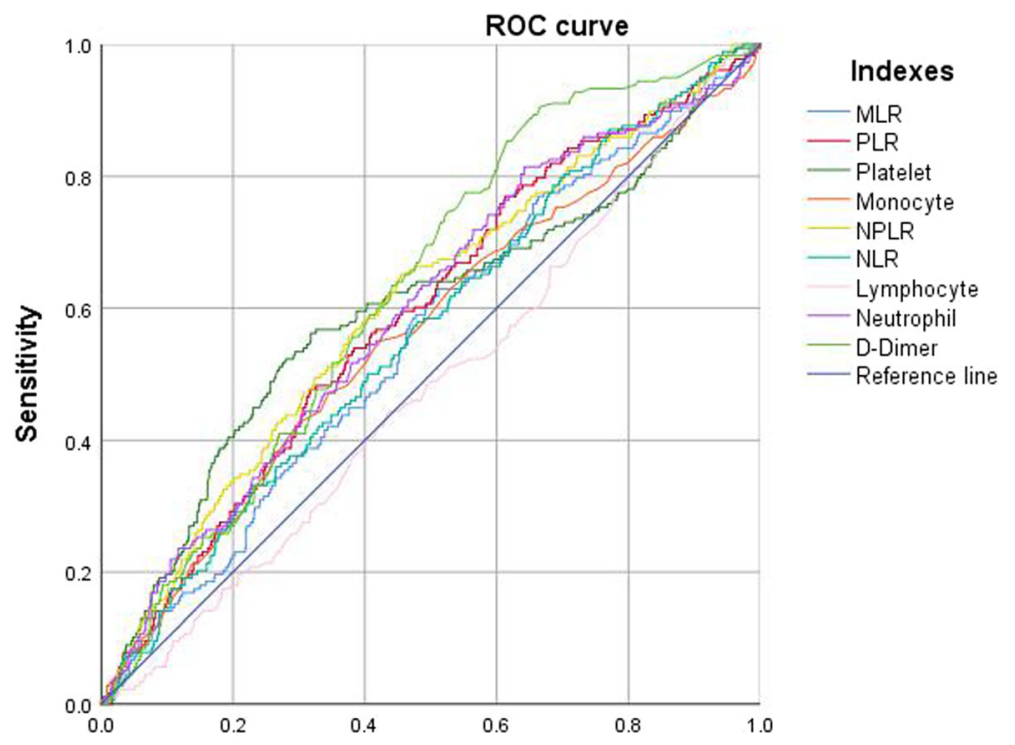

Fig. 1 ROC to determine the optimal cutoff value for each biomarker or inflammatory/immune index, when in continuous variable

The systemic immune-inflammation index (SII) was calculated as: platelet count $\times$ neutrophil count/lymphocyte count [20]. Given the importance in predictive ability or diagnosis of DVT, plasma D-dimer level was also included.

The other potential factors included demographics (age, gender, body mass index (BMI)), current cigarette and alcohol consumption, the comorbidities (hypertension, diabetes, chronic heart disease), and fracturerelated factors (injury mechanism (low- or high-energy trauma), open or closed fracture, fracture classification based on Schatzker classification system).

The BMI $\left(\mathrm{kg} / \mathrm{m}^{2}\right)$ was divided using the criteria recommended by the Chinese working group on obesity: normal (18.5-23.9), underweight $(<18.5)$, overweight (24.0-27.9), and obesity ( $\geq 28.0$ ) [21]. Low-energy injury was defined as an injury caused by a fall from a standing height, while fall from a height more than $2 \mathrm{~m}$ or motor accidents were defined as high-energy injury.

\section{Statistical analysis}

Continuous variables were expressed by mean and standard deviation (SD). The categorical data were expressed as number and percentage (\%) and were evaluated by chi-square or Fisher's exact test, as appropriate.

For biomarker (neutrophil, lymphocyte, monocyte, and platelet counts) and biomarker-derived inflammation/ immune indexes (NLR, PLR, MLR, and SII) and the plasma D-dimer level in continuous variable, we constructed receiver operating characteristic (ROC) to determine the optimal cutoff value for each variable, when Youden index (sensitivity + specificity -1$)$ was maximum. The significance of the ROC curve was tested using the area under the curve (AUC) analysis, with $p<$ 0.05 as significance level. On basis of the cutoff values determined, each variable was divided in to two groups, and the chi-square or Fisher's exact test was performed, as appropriate. We also constructed ROC curve and used the generated AUC to evaluate the discriminatory ability of each biomarker or inflammation/immune index, when they were in dichotomous variable.

In the multivariate logistics regression model, the included variables were those tested as statistically significant in the univariate analyses. The stepwise backward elimination method was used to exclude variables not significantly affecting the development of DVT. In the final model, variables with $p<0.10$ were retained, and

Table 1 The ROC and AUC to determine the optimal cutoff value for each index in continuous variable

\begin{tabular}{llllll}
\hline Variable & $\begin{array}{l}\text { Optimal } \\
\text { cutoff value }\end{array}$ & AUC & & $95 \% \mathrm{Cl}$ & \multirow{2}{*}{$p$} \\
\cline { 5 - 6 } & & & Lower limit & Upper limit & \\
\hline Lymphocyte & $1.24 \times 10^{9} / \mathrm{L}$ & 0.481 & 0.435 & 0.527 & 0.422 \\
Platelet & $278 \times 10^{9} / \mathrm{L}$ & 0.598 & 0.548 & 0.648 & 0.000 \\
Monocyte & $0.78 \times 10^{9} / \mathrm{L}$ & 0.562 & 0.514 & 0.610 & 0.009 \\
Neutrophil & $5.02 \times 10^{9} / \mathrm{L}$ & 0.595 & 0.549 & 0.641 & 0.000 \\
NLR & 2.90 & 0.565 & 0.520 & 0.611 & 0.006 \\
MLR & 0.50 & 0.552 & 0.506 & 0.598 & 0.028 \\
PLR & 207 & 0.591 & 0.546 & 0.636 & 0.000 \\
SII & 1066 & 0.605 & 0.559 & 0.651 & 0.000 \\
D-Dimer & $0.55 \mathrm{mg} / \mathrm{L}$ & 0.628 & 0.588 & 0.669 & 0.000 \\
\hline
\end{tabular}




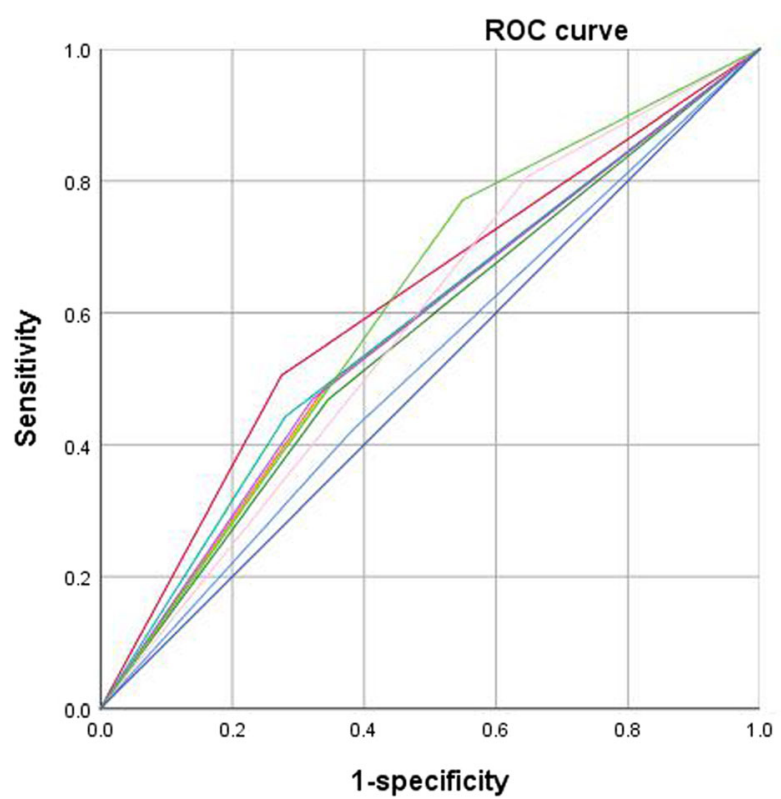

\section{Indexes}

Lymphocyte

- Platelet

-Monocyte

NLR

- MLR

- NPLR

Neutrophil

- PLR

- Ddimer

- Referebce line

1-specificity

Fig. 2 The predictive ability (sensitivity, specificity, and AUC) of each biomarker or inflammatory/immune index, when in dichotomous variable

the correlation strength is indicated by odds ratio (OR) and $95 \%$ confidence interval $(95 \% \mathrm{CI})$. The significance level was $p<0.05$. Fitting degree of the final model was evaluated by Hosmer-lemeshow (H-L) test, and $p>0.05$ indicated the acceptable result. SPSS23.0 was used to perform all the tests (IBM, armonk, New York, USA).

\section{Results}

In this study, a total of 1179 patients with tibial plateau fractures were included, consisting of 742 males and 437 females, with an average of 45.6 years (Sd, 13.6; range, 18-82). The mean days from admission to operation were $4.2 \pm 4.9$ days ( $0-16$ days). A total of 192 (16.3\%) had a preoperative DVT. The preoperative DUS was performed at a mean of $3.9 \pm 3.6$ days (range 0-17 days) after injury, by 5 different technicians.
The optimal cutoff value for each biomarker or inflammation/immune index was as follows: neutrophil count, $5.02 \times 10^{9} / \mathrm{L}$; lymphocyte count, $1.24 \times 10^{9} / \mathrm{L}$; monocyte, $0.78 \times 10^{9} / \mathrm{L}$; platelet count, $278 \times 10^{9} / \mathrm{L} ; \mathrm{NLR}, 2.90$; PLR, 207; MLR, 0.50; SII, 1066; and D-dimer, $0.55 \mathrm{mg} / \mathrm{L}$ (Fig. 1 and Table 1). When evaluated as categorical variables, the AUC showed the best discrimination ability for PLT (AUC, 0.615; 95\% CI, 0.570-0.660), followed by D-dimer (AUC, 0.611; 95\% CI, 0.570-0.652) (Fig. 2 and Table 2).

From the univariate analyses, we could find that the rate of DVT was significantly different between patients and non-DVT patients in terms of gender, prevalence of hypertension, current smoking, open fracture, fracture type based on Schartzker classification system, platelet, monocyte, neutrophile, NLR, PLR, MLR, and SII (Table 3).

Table 2 The ROC and AUC to evaluate the discriminatory ability of each index in categorical variable

\begin{tabular}{|c|c|c|c|c|c|c|}
\hline \multirow[t]{2}{*}{ Variable } & \multirow[t]{2}{*}{ Sensitivity } & \multirow[t]{2}{*}{ Specificity } & \multirow[t]{2}{*}{ AUC } & \multicolumn{2}{|l|}{$95 \% \mathrm{Cl}$} & \multirow[t]{2}{*}{$p$} \\
\hline & & & & Upper limit & Lower limit & \\
\hline Lymphocyte & 0.422 & 0.618 & 0.520 & 0.475 & 0.565 & 0.381 \\
\hline Platelet & 0.505 & 0.715 & 0.615 & 0.570 & 0.660 & 0.000 \\
\hline Monocyte & 0.469 & 0.655 & 0.562 & 0.517 & 0.607 & 0.007 \\
\hline Neutrophil & 0.807 & 0.352 & 0.579 & 0.538 & 0.621 & 0.000 \\
\hline NLR & 0.490 & 0.658 & 0.574 & 0.529 & 0.618 & 0.001 \\
\hline MLR & 0.490 & 0.653 & 0.572 & 0.527 & 0.616 & 0.002 \\
\hline PLR & 0.469 & 0.679 & 0.574 & 0.529 & 0.619 & 0.001 \\
\hline SII & 0.557 & 0.719 & 0.581 & 0.536 & 0.626 & 0.000 \\
\hline D-dimer & 0.771 & 0.451 & 0.611 & 0.570 & 0.652 & 0.000 \\
\hline
\end{tabular}


Table 3 Univariate analyses of factors associated with preoperative DVT following tibial plateau fracture

\begin{tabular}{|c|c|c|}
\hline Variables & DVTs/total (incidence) & $P$ \\
\hline Gender & & 0.003 \\
\hline Male & 139/742 (18.7\%) & \\
\hline Female & $53 / 437(12.1 \%)$ & \\
\hline Age & & 0.108 \\
\hline $18-44$ & $81 / 558(14.5 \%)$ & \\
\hline $45-64$ & $96 / 509(18.9 \%)$ & \\
\hline 65 or older & $15 / 112(13.4 \%)$ & \\
\hline \multicolumn{3}{|l|}{ BMI $\left(\mathrm{kg} / \mathrm{m}^{2}\right)$} \\
\hline $18.5-23.9$ & $44 / 362(12.2 \%)$ & \\
\hline$<18.5$ & $2 / 21(9.5 \%)$ & \\
\hline $24.0-27.9$ & 102/511 (20.0\%) & \\
\hline$\geq 28.0$ & $44 / 286(15.4 \%)$ & \\
\hline Diabetes mellitus & 23/154 (14.9\%) & 0.627 \\
\hline Hypertension & $47 / 214(22.0 \%)$ & 0.013 \\
\hline Chronic heart disease & $14 / 56(25.0 \%)$ & 0.070 \\
\hline Fracture type (Schatzker) & & 0.022 \\
\hline I-IV & 133/793 (16.8\%) & \\
\hline $\mathrm{V}-\mathrm{VI}$ & $59 / 385(15.3 \%)$ & \\
\hline Mechanism (high-energy) & $120 / 758(15.8 \%)$ & 0.571 \\
\hline Open fracture & 22/71(31.0\%) & 0.001 \\
\hline Current smoking & $37 / 166(22.3)$ & 0.024 \\
\hline Alcohol consumption & 20/107 (18.7\%) & 0.480 \\
\hline D-Dimer (> 0.55 mg/L) & $148 / 690(21.4 \%)$ & $<0.001$ \\
\hline Neutrophil count (> $\left.5.02 \times 10^{9} / \mathrm{L}\right)$ & 155/795 (19.5\%) & $<0.001$ \\
\hline Lymphocyte $\left(<1.24 \times 10^{9} / \mathrm{L}\right)$ & $81 / 458(17.7 \%)$ & 0.299 \\
\hline Monocyte (> $\left.0.78 \times 10^{9} / \mathrm{L}\right)$ & 90/431 (20.9\%) & 0.001 \\
\hline Platelet $\left(>278 \times 10^{9} / \mathrm{L}\right)$ & $97 / 368(26.4 \%)$ & $<0.001$ \\
\hline NLR $(>2.90)$ & $94 / 432(21.8 \%)$ & $<0.001$ \\
\hline PLR (> 206) & $90 / 407(22.1 \%)$ & $<0.001$ \\
\hline MLR $(>0.50)$ & $94 / 436(21.6 \%)$ & $<0.001$ \\
\hline SII $(>1066)$ & $85 / 362(23.5 \%)$ & $<0.001$ \\
\hline
\end{tabular}

DVT deep vein thrombosis, BMI body mass index, NLR neutrophil to lymphocyte rate, $P L R$ platelet to lymphocyte rate, $M L R$ monocyte to lymphocyte rate, SII systemic immune-inflammation index

In the final multivariate logistic regression model, four risk factors were identified to be associated with DVT, including open fracture, neutrophil $(>5.02 \times$ $\left.10^{9} / \mathrm{L}\right)$, D-dimer level $(>0.55 \mathrm{mg} / \mathrm{L})$, and PLT $>278 \times$ $10^{9} / \mathrm{L}$ (Table 4). The H-L test showed the good fitness $\left(X^{2}=2.428, p=0.787\right.$; Nagelkerke $\left.R^{2}=0.111\right)$.

We also performed the sensitivity analysis after excluding the 71 open fractures. The results showed that neutrophil $\left(>5.02 \times 10^{9} / \mathrm{L}\right)$, D-dimer level $(>0.55$ $\mathrm{mg} / \mathrm{L}$ ), and PLT $>278 \times 10^{9} / \mathrm{L}$ remained significant in the multivariate model. Also, the gender (male vs female) and hypertension were identified to be associated with occurrence of DVT (Table 4). The H-L test showed the good fitness $\left(X^{2}=5.668, p=0.684\right.$; Nagelkerke $\left.R^{2}=0.127\right)$.

\section{Discussion}

This study demonstrated that several commonly used biomarker-based inflammatory/immune indexes as NLR, PLR, MLR, and SII were not independently associated with the occurrence of preoperative DVT after tibial plateau fractures. Platelet count and neutrophil count were demonstrated to be independent risk factors associated with DVT, regardless of injury type. Specified at closed tibial plateau fractures, male gender and hypertension were also identified as independent risk factors for DVT.

Over the past decade, many peripheral hemogramderived indexes such as NLR, PLR, LMR, and SII demonstrated to be closely associated with systemic inflammation/immune response status, and be of predictive value in prognosis of various infectious, oncological, and autoimmune diseases [22-25]. The underlying mechanism might be the cascade of inflammatory cytokines and chemokines, which were initiated by inflammation dysfunctional lymphocytes, provoked neutrophil, and macrophage aggregation [26]. More recently, these inflammation/immune indexes have been increasingly used in major orthopedic surgeries and were demonstrated to be associated with injury severity or perioperative complications. Barker et al. [12] found the positive relationship between increased NLR level (day 1 and day 2 , pre- and postoperative) and the risk of venous thromboembolism after total knee arthroplasty. In addition, researchers have successively reported independent association of MLR [14], NLR [27], and PLR [27] with postoperative DVT in total joint arthroplasty.

Increasing evidences have showed that inflammatory response played an important role in the development of DVT. In fact, coagulation activation and inflammation reaction were intimately related because multiple cellular factors were involved in both processes, including but not limited to monocyte, neutrophils, and platelets [28-30]. In an animal experiment, von Bruhl et al. [30] demonstrated the monocytes, neutrophils, and platelets cooperated to initiate and propagate venous thrombosis. In addition, inflammatory/immune response to trauma was the important contributing factor for development of DVT. Alexandru et al. [11] evaluated the levels of hematology panel biomarkers in 148 patients with long-bone fractures and found that patients with fractures had significantly higher NLR level, compared to controls. However, in this study, we did not demonstrate the significant relationship between any of these inflammatory/immune indexes with DVT. This might be explained by the fact that these derived indexes would have more "intersections" with the 
Table 4 Multivariate analysis of risk factors associated with DVT, with inclusion or exclusion of open fracture

\begin{tabular}{|c|c|c|c|c|c|}
\hline \multicolumn{3}{|c|}{ Multivariate analysis with open fracture included } & \multicolumn{3}{|c|}{ Sensitivity analysis with exclusion of open fracture } \\
\hline Variables & OR and $95 \% \mathrm{Cl}$ & $P$ & Variables & OR and $95 \% \mathrm{Cl}$ & $P$ \\
\hline Open fracture (vs close) & $2.30(1.30-4.07)$ & 0.004 & Gender (male vs female) & $1.71(1.17-2.49)$ & 0.006 \\
\hline D-dimer (> 0.55 mg/L) & $2.20(1.47-3.28)$ & $<0.001$ & D-dimer (> $0.55 \mathrm{mg} / \mathrm{L})$ & $2.36(1.59-3.50)$ & $<0.001$ \\
\hline Neutrophil count $\left(>5.02 \times 10^{9} / \mathrm{L}\right)$ & $1.75(1.13-1.71)$ & 0.012 & Neutrophil count $\left(>5.02 \times 10^{9} / \mathrm{L}\right)$ & $1.59(1.05-2.41)$ & 0.030 \\
\hline \multirow[t]{2}{*}{ Platelet count $\left(>278 \times 10^{9} / \mathrm{L}\right)$} & $2.42(1.71-3.42)$ & $<0.001$ & Platelet count (> $\left.278 \times 10^{9} / \mathrm{L}\right)$ & $2.66(1.88-3.75)$ & $<0.001$ \\
\hline & & & Hypertension & $1.71(1.13-2.58)$ & 0.011 \\
\hline
\end{tabular}

original hemogram indexes, and it was possible that algorithm between biomarkers did not exhibit the significant independent predictive effect on DVT.

In contrast, platelet and neutrophil count were found to be independently associated with DVT following tibial plateau fractures, regardless of the injury type. It is therefore suggested that increased number of neutrophils reflected the extent of inflammatory response, and activation of increased platelets is the necessity of the formation of DVT. The previous basic researches have described different mechanisms of DVT formation, including neutrophil extracellular traps (NETs), neutrophil histone modification [31-33], and trauma-induced activation of platelets and secondary cascade reaction via secretion of aggregatory mediators [34]. In this study, we also evaluate the predictive ability of them. The sensitivity neutrophil count $>5.02 \times 10^{9} / \mathrm{L}$ was 0.807 , a relatively high level, which could be used for initial screening of patients at-risk of DVT. The sensitivity of platelet count $>278 \times 10^{9} / \mathrm{L}$ was relatively low $(0.505)$ but with a moderate specificity of 0.715 ; therefore, it might be a useful auxiliary tool to exclude patients without a DVT.

D-dimer in plasma reflected the secondary increased fibrinolytic activity and the hypercoagulability, which was a well-established highly sensitive marker of thrombotic events, although the specificity was poor [35]. Another concern was the concentration of Ddimer varied in different settings. For example, Ddimer concentration increased with age; therefore, several studies suggested the use of age-adjusted cutoff values in patients with suspected DVT $[36,37]$. In this study, we determined that the optimal cutoff value of D-dimer level was 0.55 , slightly higher than the commonly used values, which might be associated with setting of trauma. The multivariate analysis showed that DVT $>0.55 \mathrm{mg} / \mathrm{L}$ was associated with 2.42-fold risk of DVT in overall patients, and with 2.36 -fold risk in patients with closed fractures. This result demonstrated the stability of D-dimer in predicting or diagnosing DVT. We re-confirmed the low specificity D-dimer that was 0.451 , higher than that of the previous studies in different settings, even with age-adjusted values used [37].
This study had some limitations. Firstly, as other multivariate analyses, not all the potential factors that affect the occurrence of DVT could be included, such as immobilisation of the injured extremity. As such, the residual confoundings remained. Secondly, C-reaction protein (CRP) was an important inflammatory biomarker predictive of DVT formation, but only a fraction of patients had the relevant data because it was not routinely measured in our hospital. Thirdly, the AUC for Ddimer, platelet, and neutrophil count was 0.628, 0.698, and 0.595 , respectively, which indicated the moderate to poor predictive ability or reliability for DVT. Therefore, they should be treated cautiously, and in the current condition, combined diagnostic method with these factors may be a settlement. Fourthly, we determined the association rather than the causation between variables and DVT; therefore, these results should be interpreted with caution. Fifthly, this is a tertiary referral hospital, and patients referred would have more severe injury; therefore, the prevalence of DVT might be overestimated, and the generalizability of the results might be somewhat affected.

In summary, $16.3 \%$ of patients had preoperative DVT after tibial plateau fracture, and among the common biomarkers or biomarker-based inflammatory/immune indexes, only platelet and neutrophil were identified to be associated with development of DVT, regardless of injury pattern. These factors are conducive to the initial screening for patients at risk of DVT, individualized risk assessment, risk stratification, and accordingly development of targeted prevention programs.

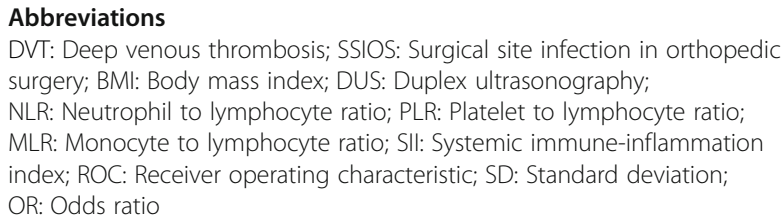

\section{Acknowledgements}

We are grateful to M Li and K Zhan of the Department of Orthopedics and to K Wang and J Zhang of the Department of statistics and applications for their kind assistance.

\section{Authors' contributions}

Yingze Zhang and Wei Chen conceived the idea for the study; Yanbin Zhu and Dawei Liu designed the study. Kuo Zhao, Junzhe Zhang, Hongyu Meng, 
and Junyong Li collected the relevant data. Dawei Liu and Junyong Li prepared the figures and tables. Wei Chen performed the statistical analyses. All the authors interpreted the data and contributed to preparation of the manuscript. Dawei Liu and Yanbin contributed equally to this manuscript. The authors read and approved the final manuscript.

\section{Funding}

This study was supported by Hebei Provincial Department of Human Resources and Social Security Funding NO A201903007.

\section{Availability of data and materials}

All the data will be available upon motivated request to the corresponding author of the present paper

\section{Ethics approval and consent to participate}

This study was approved by the ethics committee of the 3rd Hospital of Hebei Medical University. Informed consent was obtained from all the participants.

\section{Consent for publication}

Written informed consent was obtained from each patient to authorize the publication of their data.

\section{Competing interests}

The authors declare that they have no competing interests.

\section{Author details}

1 Department of Orthopaedic Surgery, Tianjin Nankai Hospital, Tianjin 300100 P. R. China. ${ }^{2}$ Department of Orthopaedic Surgery, The 3rd Hospital of Hebei Medical University, Shijiazhuang 050051, Hebei, P. R. China. ${ }^{3}$ Key Laboratory of Biomechanics of Hebei Province, Shijiazhuang 050051, Hebei, P. R. China. ${ }^{4}$ Orthopaedic Institution of Hebei Province, Shijiazhuang 050051, Hebei, P. R. China. ${ }^{5}$ Chinese Academy of Engineering, Beijing 100088, P. R. China.

Received: 5 May 2020 Accepted: 26 June 2020

Published online: 02 July 2020

\section{References}

1. Zhang Y. Clinical epidemiology of orthopedic trauma: Thieme; 2012

2. Elsoe R, Larsen P, Nielsen NPH, Swenne J, Rasmussen S, Ostgaard SE. Population-based epidemiology of tibial plateau fractures. Orthopaedics. 2015;38(9):e780-6.

3. Lapidus LJ, Rosfors S, Ponzer S, Levander C, Elvin A, Lärfars G, et al. Prolonged thromboprophylaxis with dalteparin after surgical treatment of achilles tendon rupture: a randomized, placebo-controlled study. J Orthop Trauma. 2007;21(1):52-7.

4. Lapidus LJ, Ponzer S, Elvin A, Levander C, Lärfars G, Rosfors S, et al. Prolonged thromboprophylaxis with dalteparin during immobilization after ankle fracture surgery: a randomized placebo-controlled, double-blind study. Acta Orthop. 2007;78(4):528-35.

5. Wang J, Zhao CP, Wei J, Wang MY. Risk factors of deep venous thrombosis in lower extremity of tibial plateau fracture. Chin J Bone Joint. 2015;(2): 86-90.

6. Wang $\mathrm{H}$, Kandemir $\mathrm{U}$, Liu $\mathrm{P}$, Zhang $\mathrm{H}$, Wang $\mathrm{PF}$, Zhang $\mathrm{BF}$, et al. Perioperative incidence and locations of deep vein thrombosis following specific isolated lower extremity fractures. Injury. 2018:49(7):1353-7.

7. Coon WW. Venous thromboembolism. Prevalence, risk factors, and prevention. Clin Chest Med. 1984;5(3):391-401.

8. Huang L, Li J, Jiang Y. Association between hypertension and deep vein thrombosis after orthopedic surgery: a meta-analysis. Eur J Med Res. 2016; 21:13-9.

9. Edmonds MJ, Crichton TJ, Runciman WB, Pradhan M. Evidence-based risk factors for postoperative deep vein thrombosis. ANZ J Surg. 2015;74(12): 1082-97.

10. Williams JR, Little MT, Kramer PA, Benirschke SK. Incidence of preoperative deep vein thrombosis in calcaneal fractures. J Orthop Trauma. 2016;30(7): e242-5

11. Alexandru L, Haragus H, Deleanu B, Timar B, Poenaru DV, Vlad DC Haematology panel biomarkers for humeral, femoral, and tibial diaphyseal fractures. Int Orthop. 2019;43(7):1567-72.
12. Barker T, Rogers VE, Henriksen VT, Brown KB, Trawick RH, Momberger NG, et al. Is there a link between the neutrophil-to-lymphocyte ratio and venous thromboembolic events after knee arthroplasty? A pilot study. J Orthop Traumatol. 2016;17(2):163-8.

13. Ming L, Jiang Z, Ma J, Wang Q, Wu F, Ping J. Platelet-to-lymphocyte ratio, neutrophil-to-lymphocyte ratio, and platelet indices in patients with acute deep vein thrombosis. VASA Zeitschrift fur Gefasskrankheiten. 2018;47(2): $143-7$.

14. Zhu X, Yao Y, Yao C, Jiang Q. Predictive value of lymphocyte to monocyte ratio and monocyte to high-density lipoprotein ratio for acute deep vein thrombosis after total joint arthroplasty: a retrospective study. J Orthop Surg Res. 2018;13(1):211-8.

15. Artoni A, Abbattista M, Bucciarelli P, Gianniello F, Scalambrino E, Pappalardo $E$, et al. Platelet to lymphocyte ratio and neutrophil to lymphocyte ratio as risk factors for venous thrombosis. Clin Applied Thrombosis/hemostasis. 2018;24(5):808-14

16. association VsgoCm. Guidelines for the diagnosis and treatment of deep vein thrombosis (3rd edition). Chin J Gen Surg. 2017;32(9):807-12.

17. Cogo A, Lensing AWA, Koopman MMW, Piovella F, Siragusa S, Wells PS, et al. Compression ultrasonography for diagnostic management of patients with clinically suspected deep vein thrombosis: prospective cohort study. BMJ. 1998;316(7124):17-20.

18. Solis G, Saxby T. Incidence of DVT following surgery of the foot and ankle. Foot \& Ankle International. 2002;23(5):411-4.

19. Elfandi A, Anghel S, Sales C. Current management of isolated soleal and gastrocnemius vein thrombosis, J Vasc Surg venous Lymphat Disord. 3(3): 341-4.

20. Hu B, Yang XR, Xu Y, Sun YF, Sun C, Guo W, et al. Systemic immuneinflammation index predicts prognosis of patients after curative resection for hepatocellular carcinoma. Clin Cancer Res. 2014;20(23):6212-22.

21. Zhu Y, Liu S, Zhang X, Chen W, Zhang Y. Incidence and risks for surgical site infection after adult tibial plateau fractures treated by ORIF: a prospective multicentre study: SSI after tibial plateau fracture. Int Wound J. 2017;14(6): 982-8.

22. Hu B, Yang $X-R, X u Y$, Sun $Y-F$, Sun C, Guo W, et al. Systemic immuneinflammation index predicts prognosis of patients after curative resection for hepatocellular carcinoma. Clin Cancer Res. 20(23):6212-22.

23. Zaragoza J, Kervarrec T, Touzé A, Avenel-Audran M, Beneton N, Esteve E, et al. A high neutrophil-to-lymphocyte ratio as a potential marker of mortality in patients with Merkel cell carcinoma: a retrospective study. J Am Acad Dermatol. 2016 Oct;75(4):712-21.

24. Forrest EH, Storey N, Sinha R, Atkinson SR, Hayes PC. Baseline neutrophil-tolymphocyte ratio predicts response to corticosteroids and is associated with infection and renal dysfunction in alcoholic hepatitis. Aliment Pharmacol Ther. 2019;50(4):442-53.

25. Berna S, Sevimli DB, Cihan CN, Teoman E. Neutrophil to lymphocyte ratio in patients with vitiligo. Postepy Dermatol Alergol. 2017:34(5):468-70.

26. Weitzmann MN. T-cells and B-cells in osteoporosis. Curr Opin Endocrinol Diab Obesity. 2014;21(6):461-7.

27. Yao C, Zhang Z, Yao Y, Xu X, Jiang Q, Shi D. Predictive value of neutrophil to lymphocyte ratio and platelet to lymphocyte ratio for acute deep vein thrombosis after total joint arthroplasty: a retrospective study. J Orthop Surg Res. 2018:13(1):40-6.

28. Borgel D, Bianchini E, Lasne D, Pascreau T, Saller F. Inflammation in deep vein thrombosis: a therapeutic target? Hematology (Amsterdam, Netherlands). 2019;24(1):742-50.

29. Hassanian SM, Avan A, Ardeshirylajimi A. Inorganic polyphosphate: a key modulator of inflammation. J Thromb Haemost. 2017;15(2):213-8.

30. von Bruhl ML, Stark K, Steinhart A, Chandraratne S, Konrad I, Lorenz M, et al. Monocytes, neutrophils, and platelets cooperate to initiate and propagate venous thrombosis in mice in vivo. J Exp Med. 2012;209(4): 819-35.

31. Brill A, Fuchs TA, Savchenko AS, Thomas GM, Martinod K, De Meyer SF, et al. Neutrophil extracellular traps promote deep vein thrombosis in mice. J Thromb Haemost. 2012;10(1):136-44.

32. Martinod K, Demers M, Fuchs TA, Wong SL, Brill A, Gallant M, et al. Neutrophil histone modification by peptidylarginine deiminase 4 is critical for deep vein thrombosis in mice. Proc Natl Acad Sci U S A. 2013;110(21): 8674-9.

33. Brinkmann V. Neutrophil extracellular traps in the second decade. J Innate Immunity. 2018;10(5-6):414-21. 
34. Koupenova M, Kehrel BE, Corkrey HA, Freedman JE. Thrombosis and platelets: an update. Eur Heart J. 2017;38(11):785-91.

35. Wells PS, Anderson DR, Rodger M, Forgie M, Kearon C, Dreyer J, et al. Evaluation of D-dimer in the diagnosis of suspected deep-vein thrombosis. N Engl J Med. 2003;349(13):1227-35.

36. Douma RA, Tan M, Schutgens RE, Bates SM, Perrier A, Legnani C, et al. Using an age-dependent $\mathrm{D}$-dimer cut-off value increases the number of older patients in whom deep vein thrombosis can be safely excluded. Haematologica. 2012;97(10):1507-13.

37. Schouten HJ, Geersing GJ, Koek HL, Zuithoff NP, Janssen KJ, Douma RA, et al. Diagnostic accuracy of conventional or age adjusted D-dimer cut-off values in older patients with suspected venous thromboembolism: systematic review and meta-analysis. Bmj. 2013;346:2492-505.

\section{Publisher's Note}

Springer Nature remains neutral with regard to jurisdictional claims in published maps and institutional affiliations.

Ready to submit your research? Choose BMC and benefit from:

- fast, convenient online submission

- thorough peer review by experienced researchers in your field

- rapid publication on acceptance

- support for research data, including large and complex data types

- gold Open Access which fosters wider collaboration and increased citations

- maximum visibility for your research: over $100 \mathrm{M}$ website views per year

At BMC, research is always in progress.

Learn more biomedcentral.com/submissions 